\title{
COMPARATIVE EVALUATION OF THE ORIGIN, EVOLUTION, TRANSMISSION, DIAGNOSIS, AND VACCINE DEVELOPMENT OF THREE HIGHLY PATHOGENIC HUMAN CORONAVIRUSES (SARS-COV, MERS-COV AND SARS-COV-2)
}

\author{
Prabhu Dutta Shaw ${ }^{1}$ (D), Nicky Patel $^{2}$, Shailee Patil ${ }^{2}$, Richard Samuel ${ }^{2}$, Prateek Khanna ${ }^{3}$, \\ Bhumika Prajapati $^{2}$ (D), Khan Sharun ${ }^{4}$ (D), Ruchi Tiwari ${ }^{5}$ (D), \\ Kuldeep Dhama $^{6 *}$ (D), Senthilkumar Natesan ${ }^{2 *}$ (D)

\footnotetext{
${ }^{1}$ Prasanna School of Public Health, Manipal Academy of Higher Education, Eshwar Nagar, Manipal, Udupi, Karnataka - 576104, India

${ }^{2}$ Indian Institute of Public Health Gandhinagar, Opp to Airforce station HQ, Lekawada, Gandhinagar, Gujarat - 382042, India

${ }^{3}$ Indian Institute of Public Health - Delhi, Plot No. 47, Sector 44, Institutional Area, Gurugram - 122002, India

${ }^{4}$ Division of Surgery, ICAR-Indian Veterinary Research Institute, Izatnagar, Bareilly-243 122, Uttar Pradesh, India

${ }^{5}$ Department of Veterinary Microbiology and Immunology, College of Veterinary Sciences, Uttar Pradesh Pandit Deen Dayal Upadhyaya Pashu Chikitsa Vigyan Vishwavidyalaya Evam Go Anusandhan Sansthan (DUVASU), Mathura, India -281001, India.

${ }^{6}$ Division of Pathology, ICAR-Indian Veterinary Research Institute, Izatnagar, Bareilly- 243 122, Uttar Pradesh, India
} \\ Received - October 05, 2020; Revision - October 20, 2020; Accepted - October 28, 2020 \\ Available Online October 30, 2020
}

DOI: http://dx.doi.org/10.18006/2020.8(Spl-1-SARS-CoV-2).S103.S113

KEYWORDS
Coronaviruses
SARS-CoV
MERS-CoV
SARS-CoV-2
Transmission
Evolution
Diagnosis
Vaccines

* Corresponding author

E-mail: snatesan@iiphg.org (Senthilkumar Natesan); kdhama@ rediffmail.com (Kuldeep Dhama)

Peer review under responsibility of Journal of Experimental Biology and Agricultural Sciences.

Production and Hosting by Horizon Publisher India [HPI] (http://www.horizonpublisherindia.in/).

All rights reserved.

\begin{abstract}
Coronavirus infection in humans is not uncommon. The first coronavirus (HCoV-229E) in humans was isolated in 1965. Subsequently, three more coronaviruses were recognized: HCoV-NL63, HCoV-HKU1, and $\mathrm{HCoV}-229 \mathrm{E}$. These viruses are endemic in humans and cause common cold and mild respiratory infections throughout the year. The three coronaviruses, SARS-CoV, MERS-CoV, and SARS-CoV-2 are highly pathogenic coronaviruses that cause very severe respiratory diseases in human. SARS-CoV-2 is a newly emerging coronavirus posing pandemic COVID-19 disease that has disrupted the human life in many ways. In this review, the origin, evolution, transmission, vaccine development, and clinical characteristics of these highly pathogenic human coronaviruses are compared and discussed to understand the common and different features of these viruses and their relevance to develop a successful vaccine to control the pandemic COVID-19.
\end{abstract}

All the articles published by Journal of Experimental Biology and Agricultural Sciences are licensed under a Creative Commons Attribution-NonCommercial 4.0 International License Based on a work at www.jebas.org.

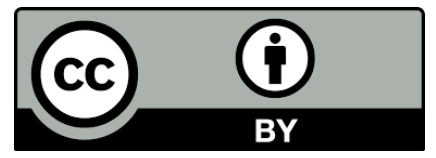




\section{Introduction}

Coronaviruses (CoVs), which belong to family Coronaviridae, are positive single-stranded RNA (ssRNA) viruses that have spike-like glycoproteins present on the envelope, which gives a crown-like appearance to it when observed under an electron microscope. The ssRNA genome is about $30 \mathrm{~kb}$ in size. The CoVs form enveloped spherical particles which are of size $100-160 \mathrm{~nm}$ in diameter. The 5 '-terminal two-thirds of the coronavirus genome is seen to encode pp1ab, a polyprotein, which is cleaved into 16 non-structural proteins that take part in the process of genome transcription and replication. The 3 ' terminus of the coronavirus encodes structural proteins that include nucleocapsid $(\mathrm{N})$, membrane $(\mathrm{M})$, envelope (E), and envelope glycoproteins spike (S) (Fehr \& Perlman, 2015; Dhama et al., 2020a).

The Coronaviridae family (order Nidovirales) has the subfamily Orthocoronavirinae which is further classified into four genera of Coronaviruses, which includes the Alpha coronavirus (alphaCoV), the Beta coronavirus (betaCoV), the Delta coronavirus (deltaCoV), and the Gamma coronavirus (gammaCoV). BetaCoV is then further divided into five sub-genera. It has been observed through genomic characterization that rodents and bats are the probable gene sources of alphaCoVs and betaCoVs, whereas possible gene sources of deltaCoVs and gammaCoVs come from the avian species (Cascella et al., 2020). In humans, coronaviruses can lead to severe respiratory syndrome (Cui et al., 2019). The genomes of Middle East Respiratory Syndrome Coronavirus (MERS-CoV) are divided into two clades: clade A and clade B. Only a few strains of MERS CoV belong to clade A, whereas most of them belong to clade B. There are accessory genes, in addition to the genes encoding the structural proteins that are specific to the species and are dispensable for virus replication (Cui et al., 2019). This review article highlights three pathogenic human coronaviruses viz., Sever Acute Respiratory Syndrome Coronavirus (SARS-CoV), MERS$\mathrm{CoV}$ and Sever Acute Respiratory Syndrome Coronavirus - 2 (SARS-CoV-2) (Dhama et al., 2020a; Rabaan et al., 2020) with a focus on their origin, evolution, transmission, advances in diagnosis and developing vaccines. Of these, SARS-CoV-2 is currently posing devastating pandemic of coronavirus disease 2019 (COVID-19).

\section{Severe Acute Respiratory Syndrome Coronavirus (SARS-} $\mathrm{CoV})$

\subsection{Origin and evolution}

SARS-CoV was thought to be an animal virus from an uncertain receiver-bat, and it was spread to the other animals. Around November 2002, SARS first emerged in Guangdong, China (Zhong et al., 2003; Xu et al., 2004). Most of the individuals who were affected, upon investigation were found to have had contact with the live-game trade during November and December 2002
(Xu et al., 2004). As SARS was seen to cause clusters of diseases in healthcare workers and families, it was described as "infectious atypical pneumonia" (Zhong \& Zeng, 2003). It was found to be a novel coronavirus which was not previously endemic in humans that was the pathogen causing SARS (Drosten et al., 2003; Ksiazek et al., 2003; Peiris et al., 2003). The absence of any serological evidence among healthy humans regarding prior infection proposed that SARS-CoV had newly appeared in humans. The SARS epidemic had infected more than 8000 people in 2003 from around 26 countries.

\subsection{Transmission}

Person-to-person contact is the primary route of transmission for SARS. When a person infected with SARS-CoV coughs or sneezes, it readily gets transmitted by respiratory droplets. Droplets of cough or sneeze are propelled from the infected person at a short distance through air. This can later get deposited on mucous membrane of nose, mouth, and eyes of a nearby person. Also, it can be spread by touching contaminated surfaces or objects with infectious droplets. The animal-to-human interspecies transmission was considered to be the most likely reason for the emergence of SARS. Nasal and fecal swabs were collected from apparently healthy animals such as raccoon dogs (Nyctereutes procyonoides) and Himalayan palm civets (Paguma larvata), which were kept for taking part in the live game markets in Guangdong province, and RT-PCR was done which showed the presence of a SARS coronavirus-like virus having around $99 \%$ nucleotide homology to the SARS-CoV that had then emerged in humans (Guan et al., 2003). It was found upon testing that, although there was no prior history of a SARS-like disease among the workers of the live game trade who handled animals, they had developed an antibody to the associated animal SARS coronavirus-like virus (Centers for Disease Control and Prevention, 2003; Guan et al., 2003). It is possible that these wild-game animal markets in the Guangdong province of China provided the crossing point allowing the animal precursor SARS-CoV-like virus to be transmitted to humans, which then adapted to more efficient human-to-human transmission, which thus led to the emergence of SARS (Klempner \& Shapiro, 2004). The potential SARS-CoV transmission routes were studied using models that simulated in-flight infections in an aircraft cabin environment. The findings indicated higher proportion of in-flight transmission via fomite route (50\%) which was followed by close contact (29\%), and airborne transmission (21\%) (Lei et al., 2018).

\subsection{Laboratory Diagnosis}

Several laboratory tests can be carried out for the detection of SARS-CoV, including RT-PCR. Various clinical specimens, such as nasal secretions, blood, and stool, can be used to detect the virus using RT-PCR. The samples were taken from the respiratory tract; 
feces and urine can also be cultured for detecting SARS-CoV (Chan et al., 2004). With the help of electron microscopic studies of mucosal biopsies collected from gastrointestinal tract of patients with SARS, the replication of SARS-CoV in the gastrointestinal tract was established (Leung et al., 2003). These findings suggest that SARS-CoV infection can also be due to fecal-oral transmission and is not just confined to the airborne spread affecting the respiratory tract. The diagnosis of pneumonia in all patients affected by SARS can be confirmed by radiography. The white blood cell count is seen to be slightly decreased whereas, the lymphocyte count was significantly reduced among the SARS patients.

The diagnosis of SARS-CoV mainly relies on laboratory-based tests as the clinical manifestations are non-specific compared to other respiratory pathogens. Therefore, a rapid simple, colorimetric, and multiplex loop-mediated isothermal amplification (LAMP) assay was developed for on-site detection as an effort to prevent future SARS-CoV outbreaks (Kim et al., 2019). The LAMP assay can be used to obtain faster result as compared to the conventional PCR method making it not only suitable for diagnostic clinical test, but also for disease surveillance in developing countries.

\subsection{Clinical characteristics}

All patients affected by SARS-CoV tend to have a high fever $\left(>38^{\circ} \mathrm{C}\right)$ and are likely to develop pneumonia. Most of the patients affected by SARS-CoV present breathlessness; some have fatigue and myalgia, and very few show other mild symptoms suggestive of respiratory infection, such as sore throat and cough (Zhong et al., 2003). Among the outbreak areas, the mortality rate varied widely and was found to be around $0 \%$ to $17.1 \%$. Most of the regions which were first affected, for instance, Guangdong, experienced mortality rates of about $4 \%$ to $10 \%$ whereas, other areas that were affected later, for example, Singapore, had a mortality rate of around $13 \%$ to $17 \%$ (Wang \& Jolly, 2004).

\subsection{Vaccine development against SARS-CoV}

Infection with SARS-CoV can produce specific $\operatorname{IgG}$ and $\operatorname{IgM}$ antibodies against SARS-CoV as soon as two weeks of postinfection and can remain until 180 days after infection (Mo et al., 2005). Along with the high titer of the antibodies, SARS-CoV specific cytotoxic $\mathrm{T}$ lymphocytes have also been detected from the recovered patients, which suggested the role of both humoral and cellular immune response for clearance of infection $(\mathrm{Xu} \& \mathrm{Gao}$, 2004; Zhong et al., 2005). The activation of the humoral and cellular immune response can be possible by several SARS-CoV proteins such as pp1a, pp1b, and nucleocapsid $(\mathrm{N})$, membrane $(\mathrm{M})$, envelope (E), and spike (S) proteins. Among all, the immune response induced by the $S$ protein plays an essential role in fighting against SARS-CoV infection (Liu et al., 2014). It is taking part in the receptor recognition, attachment, and virus entry mechanism. Therefore, it is considered an essential target for the SARS vaccine development and its therapeutics (Zhang et al., 2006). The $S$ protein-based vaccine could induce antibodies to block virus binding and its fusion, thereby neutralizing the virus infection. The subunits, full-length protein, and receptor-binding domain (RBD) of $\mathrm{S}$ protein-based vaccines were under development. The antibodies that are raised to amino acids 485 625 and 1029-1192 sequences in S1 proteins have been found to neutralize the SARS-CoV infection in Vero E6 cells (Zhou et al., 2004). When African green monkeys were immunized with an attenuated parainfluenza virus that was encoded with full-length SARS-CoV S protein, it induced specific neutralizing antibodies to be produced, which helped to protect the vaccinated monkeys from getting infected with subsequent homologous SARS-CoV-like infections. This suggests that in order to prevent SARS-CoV infection, immunization with an S protein-based vaccine is highly effective (Bukreyev et al., 2004). Yet there is a possibility that these vaccines may induce harmful immune responses, which can result in liver damage or enhanced infection due to homologous SARS-CoV-like virus among the vaccinated animals (Czub et al., 2005; Weingartl et al., 2004). Therefore, this has raised concerns on safety and efficacy of full-length SARS-CoV S protein-based vaccines.

Sublingual administration of inactivated viruses, virus-like particles, or soluble protein antigens, is another strategy that can be used to induce broad immune responses in mucosal and extramucosal tissues. The sublingual administration of recombinant replication-defective adenovirus vectors (rADVs) encoding SARS$\mathrm{CoV}$ spike protein was found to induce protective immunity through serum neutralizing and airway $\operatorname{IgA}$ antibodies in mice (Shim et al., 2012). Therefore, sublingual administration can offer safe and effective route of inducing broad spectrum of immune responses. In another study, the ability of inactivated SARS-CoV Z-1 vaccine to trigger antibody-dependent enhancement (ADE)mediated vaccine-induced infection aggravation was evaluated in rhesus macaques (Luo et al., 2018). The vaccinated animals, following the challenge with SARS-CoV, did not induce ADE in rhesus macaques, and therefore might be a good candidate for further clinical trials.

\section{Middle East Respiratory Syndrome Coronavirus (MERS-CoV)}

\subsection{Origin and evolution}

MERS is caused by a novel zoonotic beta coronavirus named MERS-CoV that was first described in June 2012 (Mackay \& Arden, 2015). The first case definition of MERS, which was defined by WHO, included cough, febrile illness, and hospitalization of people who were suspected of having lower 
respiratory tract infections. It also included people who came in contact with confirmed or probable cases or had traveled to Arabian Peninsula or were residents of there (Mackay \& Arden, 2015). The people who presented with MERS were those who, within 14 days before the onset of symptom, had either traveled near or in the Arabian peninsula; who came in close contact with the traveler(s) in whom the symptoms such as fever, and acute respiratory illness occurred within 14 days after traveling near or within Arabian peninsula; or who was one of groups of patients who showed symptoms of severe acute respiratory illness of unknown etiology (Papadakis et al., 2016). In June 2012, a 60-year older man who was hospitalized in Jeddah, Saudi Arabia, had expired due to severe pneumonia and multiorgan failure. It was in him that the MERS-CoV was first isolated.

MERS-CoV cases had originated in the Middle East countries, including Saudi Arabia, the United Arab Emirates (UAE), Iran, Kuwait, Oman, and Qatar. Around 27 countries had reported MERS cases, from which more than $80 \%$ of the cases were reported in Saudi Arabia. MERS-CoV strains that were isolated from humans were homologous to those isolated from camels. Antibodies specific to MERS-CoV were found to be highly prevalent in the camels found in Middle East, Asia, and Africa. In one of the studies conducted in Qatar, milk, and serum were collected from 33 camels, in which MERS-CoV-specific antibodies were detected. Thus, for MERS-CoV, camels are considered as the main intermediary host species. The presence of MERS-CoV among camels can be said to exist for at least 30 years because the serum samples that were collected in 1983 detected the presence of MERS-CoV infections (Cui et al., 2019). MERS-CoV was also seen in at least 14 species of bats, which belong to the two bat families named Nycteridae and Vespertilionidae. There were a total of 2494 confirmed cases of MERS-CoV by the end of November 2019. The total death reported globally was 858 , and the case fatality rate for MERS was reported as $37.1 \%$ (World Health Organization, 2020c).

\subsection{Transmission}

Although the reason for the transmission of MERS-CoV, a zoonotic virus, to humans is not entirely understood, it is believed that the humans in the Middle East must have got infected by directly or indirectly coming in contact with infected dromedary camels. The type of human exposures which has led to the infection is the most critical question that has been left unanswered. Most of the infected individuals did not come in contact with the dromedary camels directly, which is suggestive that the route of transmission to humans might have been indirect (Wernery et al., 2017).

The MERS-CoV is not easily transmitted from one person to another unless they come in close contact with each other, such as when taking care of MERS patients by health care workers and family members. MERS is transmitted through droplet infection, i.e., people get infected with MERS-CoV directly when they breathe in air that contains the virus in aerosol because an infected person has coughed there, or they can get infected indirectly by touching the objects on which the droplets have settled. The majority of the cases were seen to be due to human-to-human transmission in hospitals. All the MERS cases were found to be linked to countries within the Arabian Peninsula or near it (Hui et al., 2018). The majority of the MERS-CoV infections were due to nosocomial outbreaks, which accounted for nearly a third of the cases that were reported globally. It has been seen that MERS-CoV remains stable in aerosol at low humidity conditions and temperature $\left(20^{\circ} \mathrm{C}\right)$, and can still be recovered from steel or plastic surfaces even after $48 \mathrm{hrs}$. This is the reason for the easy transmission of MERS-CoV in the hospitals and healthcare facilities that have central air conditioning, and where aerosolgenerating procedures (AGPs) are carried out, which thereby leads to the significant nosocomial outbreak (Hui et al., 2018).

\subsection{Laboratory Diagnosis}

RT-PCR is used on serum and respiratory samples for the detection of MERS-CoV. According to WHO, nasopharyngeal swabs are said to be less sensitive as compared to the specimens that are taken from the lower respiratory tract such as sputum, bronchioalveolar lavage, tracheal aspirate, or pleural fluid (Azhar et al., 2019). If it is not possible to acquire specimens from the lower respiratory tract, both oropharyngeal and nasopharyngeal swabs are to be taken, along with serum and stool (Hui et al., 2018). Though it is easier to detect MERS-CoV in patients with higher viral load, there are not many existing data, which suggests the duration of extrapulmonary and respiratory MERS-CoV shedding (Nassar et al., 2018). Lymphopenia, leucopenia, elevated lactate dehydrogenase levels, and thrombocytopenia have been reported among MERS patients. Co-infection with communityacquired bacteria and other respiratory viruses has also been reported. Patients who were on mechanical ventilation support were reported to have developed a nosocomial fungal and bacterial infection.

\subsection{Clinical characteristics}

The MERS infected individuals can be either asymptomatic or can come with mild, moderate, and severe respiratory illness, and they show other symptoms such as cough, fever, and dyspnea., and is often complicated by associated septic shock, acute respiratory distress syndrome (ARDS), severe pneumonia, and multiorgan failure. The incubation period for MERS is between 2 to 14 days. Mild cases are seen to present with a runny nose, low-grade fever, chills, sore throat, myalgia, and dry cough. Some patients can have gastrointestinal symptoms, such as vomiting, nausea, and diarrhea. 
Patients with comorbidities or those that are immunosuppressed might be at risk of being severely affected by the disease. People who are immunosuppressed may have an atypical presentation, such as diarrhea (Chafekar \& Fielding, 2018).

There is no specific antiviral therapy for the disease. Individuals infected by MERS-CoV can seek out medical care in order to relieve symptoms. Current treatment for those severely affected includes care provided for vital-organ support. Any additional benefits of new pharmacological agents such as interferon, ribavirin, and corticosteroids remain uncertain. Respiratory support is essential in patients who show improvement by taking ribavirin for 14 days (Papadakis et al., 2016). Isolation and quarantine of cases need to be strictly followed. Infection control measures are to be strictly followed as well as the management \& care of household contacts \& hospital workers who are engaged in patient(s) care. The travelers to Saudi Arabia during the MERS outbreak are advised to practice hand washing frequently and also to avoid going near people having respiratory symptoms (Papadakis et al., 2016). Patients who are suspected of having MERS-specific symptoms within 14 days of arrival from Middle Eastern countries need to be evaluated. Any form of contact with an obviously sick animal is to be avoided. The animals that are found to be sick should never be slaughtered for the purpose of consumption. Touching nose, mouth, and eyes with unwashed hands are to be avoided. Also, personal contact such as kissing and sharing cups and utensils with sick people is to be avoided. Objects and surfaces which are frequently touched, such as doorknobs, should be regularly disinfected (Papadakiset al., 2016).

\subsection{Vaccine development against MERS-CoV}

MERS-CoV genome contains genes for non-structural proteins (NSP1-NSP16), nucleocapsid (N) protein, membrane (M) protein, envelope (E) protein, spike (S) protein, and five accessory proteins (Du et al., 2017). Although NSP16 and E protein are thought to be potential immunogens that can be used to develop live attenuated vaccines, $\mathrm{S}$ and $\mathrm{N}$ proteins are the ones that are considered to be essential for the development of vaccines (Menachery et al., 2017). Several types of vaccines, such as subunit, whole genome, DNA, live attenuated, are potential candidates for development of immunity against MERS-CoV. However, live attenuated vaccines are considered to be highly effective vaccines because of its capability for inducing immunity like the natural infection. The vaccine, which was developed previously by deleting $\mathrm{E}$ gene of the MERS-CoV (rMERS-CoV- $\Delta$ E), replicated in a single cycle and lacked infectivity. Although the live attenuated viruses-based vaccine could have a risk of causing biosafety problems because of virulence reversion, rMERS-CoV- $\Delta \mathrm{E}$ is said to have propagation defectivity due to absence of $\mathrm{E}$ protein, which would prevent the virulence reversion, thereby rendering a much safer option (Almazán et al., 2013). Recently, through the mutation of NSP16
(D130A), a live attenuated MERS coronavirus was created, which protected CRISPR-Cas9-targeted 288-330+/+ C57BL/6 mice from a mouse-adapted MERS-CoV challenge (Menachery et al., 2017).

4 Severe Acute Respiratory Syndrome Coronavirus-2 (SARSCoV-2)

\subsection{Origin and evolution}

Coronaviruses are said to be commonly seen in certain animals such as camels, cattle, bats, etc. SARS-CoV-2 has caused COVID19 pandemic. Although the origin of the virus is not yet known, it is considered that animal-to-human interspecies transmission was most likely the reason for its emergence (Dhama et al., 2020b; Tiwari et al., 2020). The earliest reports suggest that the COVID19 cases appeared first in the animal and seafood market in the city of Wuhan, China (Khandola, 2020). The ongoing COVID-19 pandemic has posed high global threats, severe socio-economic impacts and challenges to control it (Ciotti et al., 2020; Dhama et al., 2020a; Malik et al., 2020; Rodriguez-Morales et al., 2020; Sharma \& Akhoury, 2020). The S spike protein of SARS-CoV-2 binds with angiotensin-converting enzyme 2 (ACE2) receptor of the host and thus enters into host cells (Iwasaki et al., 2020).

\subsection{Transmission}

The mode of transmission of COVID-19 is through droplet infection, i.e., after an infected person coughs or sneezes, the person in close contact (around 6 feet) with him has a high possibility of getting infected. The droplets containing the virus, being heavier than air, settle on nearby surfaces or objects, and any person touching them can get infected if they then touch their eyes, nose, or mouth (Coronaviridae Study Group of the International Committee on Taxonomy of Viruses, 2020). The virus can remain infectious, ranging from 2 hours to 9 days on inanimate objects and surfaces such as plastics, glass, and metals, and in the drier and colder environment can have increased survival (Rabi et al., 2020). The contagiousness is defined by a mathematical term called Reproduction number (R0). This denotes the number of people that can get infected by the host. Although WHO estimates that the R0 for SARS-CoV-2 is between 1.4 and 2.5, a particular study suggests it can range as high as 3.58 . It may be because the SARS$\mathrm{CoV}-2$ has a longer prodromal period that the virus has a slightly higher R0, thereby increasing the contagious period of the host.

It has been also reported that a large proportion of SARS-COV-2 patients worldwide are asymptomatic, raising concerns among the global public health authorities. The asymptomatic COVID-19 patients will only have a milder clinical course that does not require hospitalization (Han et al., 2020). However, the symptoms and severity of the secondary patients infected by the 
asymptomatic patients varies according to their physical constitution. The proportion of asymptomatic individuals among the confirmed varies widely (1.95\% to $87.9 \%$ ) (Han et al., 2020). SARS-CoV-2 has been detected in the salivary secretion also (Chen et al., 2020a). The presence of virus was also investigated in the forehead sweat secretion of COVID-19 patients. However, none of the samples evaluated were tested positive for SARS-CoV2 indicating that the sweat of COVID-19 patients cannot transmit the virus even though they can be transmitted via other body fluids (Fathizadeh et al., 2020). Recently, air-borne route of transmission has also been reported to play an important role in spread of SARS-CoV-2 (Morawska \& Cao, 2020; Setti et al., 2020; Zhang et al., 2020).

\subsection{Laboratory Diagnosis}

Various diagnostic tests to detect SARS-CoV-2 / COVID-19 include computed tomography (CT), real-time RT-PCR, ELISA, sequencing, LAMP, CRISPR-based test, and point-of-care tests (Afzal, 2020; Cheng et al., 2020; Dhama et al., 2020a; Udugama et al., 2020). Commonly employed diagnostics are real time RT-PCR and rapid antigen testing. Appropriate biosafety procedures need to be followed during collection, transportation, and testing of COVID-19 samples (Karthik et al., 2020). According to the recommendation of the $\mathrm{CDC}$, for the initial diagnostic testing of SARS-CoV-2, the specimen has to be collected from the upper respiratory system for testing. Specimens collected from oropharyngeal, nasopharyngeal, and bronchoalveolar lavage can be sent for laboratory testing unless a test that is designed to analyze specimens directly, swabs collected need to be immediately placed into a sterile transport tube which contains 2-3 mL of Amies transport medium, or viral transport medium (VTM) or sterile saline. In the case of the unavailability of VTM, following the protocol of $\mathrm{CDC}$, the standard operating procedure needs to be followed to create a viral transport medium in the public health labs. The non-bacteriostatic saline and NW specimen which are used to collect samples need to be immediately placed inside a sterile transport tube. There is also the option of testing the specimen from the lower respiratory tract. For SARS-CoV-2, sputum should be collected for patients who develop a productive cough and is to be sent for testing. For patients on invasive mechanical ventilation support, a bronchoalveolar lavage sample or a lower respiratory tract aspirate should be collected and tested (Centers for Disease Control and Prevention, 2020a).

Induced sputum test is another method that can be used to detect SARS-CoV-2 in patients with COVID-19. A multi-center crosssectional study was conducted to compare and evaluate induced sputum to throat swabs for SARS-CoV-2 diagnosis. The findings from the study indicates higher positive rate for induced sputum test as compared to throat swabs $(28.6 \%$ vs $5.4 \%$, respectively) (Lai et al., 2020). Due to the lower false-negative rate, induced sputum might be more reliable as compared to throat swabs. It has been confirmed that ACE2 is expressed in salivary glands and therefore SARS-CoV-2 infection can affect salivary glands (Chen et al., 2020a). As a result, saliva can be considered as abetter diagnostic specimen for critically ill patients as it can be easily collected.

\subsection{Clinical characteristics}

Different people are affected by COVID-19 in different ways. Most infected people show mild to moderate illness with symptoms of sore throat, dry cough, fatigue, fever, and recovery without needing any hospitalization. Diarrhea, headache, conjunctivitis, loss of taste or smell, discoloration of toes or fingers, or rashes on the skin are some of the less common symptoms. Symptoms such as chest pain, breathlessness, and loss of movement or speech are severe symptoms and may require intensive care treatment. It takes 5 to 6 days on average for an infected person to show signs, though it can take up to 14 days for the same (World Health Organization, 2020a). Older people with comorbidities are at high risk of getting infected by COVID-19 and its associated mortality (Dhama et al., 2020c; Zhou et al., 2020). Other risk factors include serious illness of heart, chronic lung disease, diabetes, liver diseases, chronic kidney diseases, obesity and immunosuppression due to HIV infection, immune deficiencies, prolonged use of corticosteroids, cancer treatments, organ or bone marrow transplantation, etc. (Arumugam et al., 2020; Centers for Disease Control and Prevention, 2020b).

ACE2 has a major role in the inflammation as its downregulation may aggravate COVID-19 manifestations by promoting pathological changes in lung injury. COVID-19 patients develop acute respiratory distress syndrome (ARDS) and multiple organ failure as a result of the hyper-proinflammatory stage/cytokine storm (Iwasaki et al., 2020). At this stage, treatment with dexamethasone will have beneficial effects as it limits the cytokine storm (Sharun et al., 2020). Although COVID-19 is associated with the classical presentation of respiratory symptoms with or without pneumonia that may or may not progress into severe respiratory distress syndrome, the current evidence suggests a plethora of atypical clinical presentation. These include cardiovascular, gastrointestinal, nervous, kidney and hepatic manifestations in addition to the dermatological and thromboembolic phenomena (Dhama et al., 2020a; Philips et al., 2020). Dry mouth and amblygeustia can be considered as the initial symptoms of SARS-CoV-2 infection as the virus can affect salivary glands (Chen et al., 2020a).

\subsection{Vaccine development against SARS-CoV-2}

Due to its high virulence, there is a pressing need to develop a vaccine against COVID-19, which is both safe and effective. 
Various research groups from across the world have started to develop a vaccine against SARS-CoV-2 by gaining insights from the SARS and MERS vaccine development strategies. The RBD of $S$ protein is used for immunization antigen because of its property to activate the neutralizing antibodies, which then prevents the virus from attaching to the host cell (Al-Amri et al., 2017; Du et al., 2009). A vaccine based on nucleic acid has also proven to be a highly advanced platform to combat the emerging pathogens. There are many academic sectors and biopharmaceutical companies which are in competition to develop a prophylactic vaccine against SAR-CoV-2 by using several platforms such as mRNA, DNA, recombinant protein, adenoviral vector and others (Chen et al., 2020b; Yatoo et al., 2020).

According to WHO, around 150 vaccines are being developed against SARS-CoV-2, of these few are already under clinical trials (World Health Organization, 2020b). There are several types of vaccines, such as the mRNA vaccine, DNA vaccine, recombinant vaccines, adenovirus vaccine, live-attenuated and inactivated virus vaccines, protein subunit and plant-based vaccines which are under development to combat SARS-CoV-2 (Yatoo et al., 2020). Just after 66 days since SARS-CoV-2 was first sequenced, Moderna's mRNA-1273 based vaccine went under clinical trials, which shows that there is vast potential for nucleotide-based vaccines. It employs a synthetic lipid nanoparticle to carry the mRNA templates, which allows the immune system to help in recognizing the SARS-CoV-2's S protein (Jackson et al., 2020). AstraZeneca and Oxford University are developing a recombinant vaccine AZD1222 in order to obtain a similar effectiveness by bioengineering an adenovirus to carry DNA for S protein antigen. As the adenoviruses are immunogenic, the vaccine developed by this approach could lead to generating robust memory $\mathrm{T}$ cell and $\mathrm{B}$ cell responses, which could help in obtaining better protection with fewer doses. GlaxoSmithKline and Sanofi are together working on a protein subunit approach for development of the effective vaccine, which consists of $S$ protein antigen combined with an immunogenic adjuvant that is supposed to trigger a more robust immune response (Mullard, 2020; Yatoo et al., 2020). Sputnik V is the first registered COVID-19 vaccine whose public use has been started, while other vaccines are also in pipeline that are currently being tested in different phases of clinical trials (Sputnik, 2020; TOI Coronavirus vaccine, 2020). In India, the COVID-19 vaccine COVAXIN (an inactivated vaccine), developed by Bharat Biotech in collaboration with Indian Council of Medical Research-National Institute of Virology, is soon going to undergo Phase III human clinical trials (Bharat Biotech, 2020).

\section{Conclusion and Future Prospects}

The comparative analysis of highly pathogenic human coronaviruses revealed novel insights on their evolution, structure, transmission, clinical characteristics and their relevance to vaccine development. Bats are natural reservoirs of CoVs and all these emerging coronaviruses were passed on to humans from the bats. Though the SARS-CoV and MERS-CoV emerged in 2003 and 2012, respectively, they are highly different in their antigenic make up, transmission route, severity of clinical manifestation of the disease. There is no successful vaccine approved for the use in human against any coronavirus. However, there are studies carried out towards the development of vaccines and those studies gave novel insights on the biology of the virus and challenges involved in the developing vaccines for coronaviruses. The SARS-CoV-2 caused the pandemic and lot of progress is being made to develop a successful vaccine. Adenoviral vector or nucleic acid-based vaccines are under different stages of testing to understand their safety and efficacy. Lessons learnt from the vaccine studies of SARS-CoV and MERS-CoV need to be looked at carefully during the vaccine studies of SARS-CoV-2. The issues such as antibody mediated enhancement of infection, neutralizing antibody response, and protective antibody response need to be addressed prior to the approval of vaccines for controlling COVID-19.

\section{Author contributions}

All the authors substantially contributed to the conception, compilation of data, checking and approving the final version of the manuscript, and agree to be accountable for its contents.

\section{Acknowledgments}

All the authors acknowledge and thank their respective Institutes and Universities.

\section{Funding}

This compilation is a review article written by its authors and required no substantial funding to be stated.

\section{Conflict of Interest}

There exist no commercial or financial relationships that could, in any way, lead to a potential conflict of interest.

\section{References}

Afzal A (2020) Molecular diagnostic technologies for COVID-19: Limitations and challenges. Journal of Advanced Research 10.1016/j.jare.2020.08.002. doi:10.1016/j.jare.2020.08.002.

Almazán F, DeDiego ML, Sola I, Zuñiga S, Nieto-Torres JL, Marquez-Jurado S, Andrés G, Enjuanes L (2013) Engineering a replication-competent, propagation-defective Middle East respiratory syndrome coronavirus as a vaccine candidate. MBio 4: 1-11.

Al-Amri SS, Abbas AT, Siddiq LA, Alghamdi A, Sanki MA, AlMuhanna MK, Alhabbab RY, Azhar EI, Li X, Hashem AM (2017) 
Immunogenicity of candidate MERS-CoV DNA vaccines based on the spike protein. Scientific Reports 7: 44875.

Arumugam VA, Thangavelu S, Fathah Z, et al. (2020) COVID-19 and the World with Co-Morbidities of Heart Disease, Hypertension and Diabetes. Journal of Pure and Applied Microbiology 14(3):1623-1638. doi: 10.22207/JPAM.14.3.01

Azhar EI, Hui DS, Memish ZA, Drosten C, Zumla A (2019) The middle east respiratory syndrome (MERS). Infectious Disease Clinics of North America 33: 891-905.

Bukreyev A, Lamirande EW, Buchholz UJ, Vogel LN, Elkins WR, St Claire M, Murphy BR, Subbarao K, Collins PL (2004) Mucosal immunisation of African green monkeys (Cercopithecus aethiops) with an attenuated parainfluenza virus expressing the SARS coronavirus spike protein for the prevention of SARS. The Lancet 363: 2122-2127.

Cascella M, Rajnik M, Cuomo A, Dulebohn SC, Di Napoli R (2020) Features, evaluation and treatment coronavirus (COVID19). StatPearls Publishing. https://www.ncbi.nlm.nih.gov/books/NBK554776/, accessed on 13 July 2020.

Centers for Disease Control and Prevention (2020a) Interim Guidelines for Collecting, Handling, and Testing Clinical Specimens from Persons for Coronavirus Disease 2019 (COVID19). Available at https://www.cdc.gov/coronavirus/2019 ncov/lab/guidelines-clinical-specimens.html, accessed on 13 July 2020.

Centers for Disease Control and Prevention (2020b) People who are at higher risk for severe illness. Available at https://www.cdc.gov/coronavirus/2019-ncov/need-extraprecautions/people-at-higher-risk.html, accessed on 13 July 2020.

Centers for Disease Control and Prevention (CDC) (2003) Prevalence of IgG antibody to SARS-associated coronavirus in animal traders--Guangdong Province, China, 2003. Morbidity and Mortality Weekly Report 52: 986-987.

Chafekar A, Fielding BC (2018) MERS-CoV: understanding the latest human coronavirus threat. Viruses 10: 93.

Chan KH, Poon LL, Cheng VC, Guan Y, Hung IF, Kong J, Yam LY, Seto WH, Yuen KY, Peiris JS (2004) Detection of SARS coronavirus in patients with suspected SARS. Emerging infectious Diseases 10: 294-299.

Chen L, Zhao J, Peng J, Li X, Deng X, Geng Z, Shen Z, Guo F, Zhang Q, Jin Y, Wang L, Wang S (2020a) Detection of SARS-
CoV-2 in saliva and characterization of oral symptoms in COVID19 patients. Cell proliferation 19:e12923. doi: 10.1111/cpr.12923.

Chen WH, Strych U, Hotez PJ, Bottazzi ME (2020b) The SARSCoV-2 Vaccine Pipeline: an Overview. Current Tropical Medicine Reports Mar 3:1-4.

Cheng MP, Papenburg J, Desjardins M, Kanjilal S, Quach C, Libman M, Dittrich S, Yansouni CP (2020) Diagnostic Testing for Severe Acute Respiratory Syndrome-Related Coronavirus-2: A Narrative Review. Annals of Internal Medicine M20-1301.

Ciotti M, Ciccozzi M, Terrinoni A, Jiang WC, Wang CB, Bernardini S (2020) The COVID-19 pandemic. Critical Reviews in Clinical Labortatory Sciences 57(6):365-388.

Coronaviridae Study Group of the International Committee on Taxonomy of Viruses (2020) The species severe acute respiratory syndrome related coronavirus: classifying 2019-nCoV and naming it SARS-CoV-2. Nature Microbiology 5: 536-544.

Cui J, Li F, Shi ZL (2019) Origin and evolution of pathogenic coronaviruses. Nature Reviews Microbiology 17: 181-192.

Czub M, Weingartl H, Czub S, He R, Cao J (2005) Evaluation of modified vaccinia virus Ankara based recombinant SARS vaccine in ferrets. Vaccine 23: 2273-2279. Dhama K, Khan S, Tiwari R, Sircar S, Bhat S, Malik YS, Singh KP, Chaicumpa W, Bonilla-Aldana DK, Rodriguez-Morales AJ (2020a) Coronavirus Disease 2019-COVID-19. Clinical Microbiology Reviews 33(4):e00028-20.

Dhama K, Patel SK, Sharun K, Pathak M, Tiwari R, Yatoo MI, Malik YS, Sah R, Rabaan AA, Panwar PK, Singh KP, Michalak I, Chaicumpa W, Martinez-Pulgarin DF, Bonilla-Aldana DK, Rodriguez-Morales AJ (2020b) SARS-CoV-2 jumping the species barrier: zoonotic lessons from SARS, MERS and recent advances to combat this pandemic virus. Travel Medicine and Infectious Disease 101830. doi: 10.1016/j.tmaid.2020.101830.

Dhama K, Patel SK, Kumar R, Rana J, Yatoo MI, Kumar A, Tiwari R, Dhama J, Natesan S, Singh R, Harapan H. (2020c) Geriatric Population During the COVID-19 Pandemic: Problems, Considerations, Exigencies, and Beyond. Frontier Public Health. 8:574198. doi: 10.3389/fpubh.2020.574198.

Dhama K, Patel SK, Pathak M, Yatoo MI, Tiwari R, Malik YS, Singh R, Sah R, Rabaan AA, Bonilla-Aldana DK, RodriguezMorales AJ (2020a) An update on SARS-CoV-2/COVID-19 with particular reference to its clinical pathology, pathogenesis, immunopathology and mitigation strategies. Travel Medicine and Infectious Disease 101755. 
Du L, He Y, Zhou Y, Liu S, Zheng BJ, Jiang S (2009) The spike protein of SARS-CoV-a target for vaccine and therapeutic development. Nature Review Microbiology 7: 226-236.

Du L, Yang Y, Zhou Y, Lu L, Li F, Jiang S (2017) MERS-CoV spike protein: a key target for antivirals. Expert Opinion on Therapeutic Targets 21: 131-143.

Drosten C, Günther S, Preiser W, Van Der Werf S, Brodt HR, Becker S, Rabenau H, Panning M, Kolesnikova L, Fouchier RA, Berger A. (2003) Identification of a novel coronavirus in patients with severe acute respiratory syndrome. New England Journal of Medicine 348: 1967-1976.

Fathizadeh H, Taghizadeh S, Safari R, Khiabani SS, Babak B, Hamzavi F, Ganbarov K, Esposito S, Zeinalzadeh E, Dao S, Köse Ş, Kafil HS (2020) Study presence of COVID-19 (SARS-CoV-2) in the sweat of patients infected with Covid-19. Microbial pathogenesis 149:104556. doi: 10.1016/j.micpath.2020.104556.

Fehr AR, Perlman S (2015) Coronaviruses: an overview of their replication and pathogenesis. Methods in Molecular Biology 1282:1-23. doi: 10.1007/978-1-4939-2438-7_1.

Guan Y, Zheng BJ, He YQ, Liu XL, Zhuang ZX, Cheung CL, Luo SW, Li PH, Zhang LJ, Guan YJ, Butt KM (2003) Isolation and characterization of viruses related to the SARS coronavirus from animals in southern China. Science 302: 276-278.

Han D, Li R, Han Y, Zhang R, Li J (2020) COVID-19: Insight into the asymptomatic SARS-COV-2 infection and transmission. International journal of biological sciences 16(15):2803-2811. doi: 10.7150/ijbs.48991.

Bharat Biotech (2020) Available https://www.bharatbiotech.com/covaxin.html. Accessed October 10, 2020.

Hui DS, Azhar EI, Kim YJ, Memish ZA, Oh MD, Zumla A. (2018) Middle East respiratory syndrome coronavirus: risk factors and determinants of primary, household, and nosocomial transmission. The Lancet Infectious Diseases 18: e217-e227.

Iwasaki M, Saito J, Zhao H, Sakamoto A, Hirota K, Ma D (2020) Inflammation Triggered by SARS-CoV-2 and ACE2 Augment Drives Multiple Organ Failure of Severe COVID-19: Molecular Mechanisms and Implications. Inflammation 1-22. doi: 10.1007/s10753-020-01337-3.

Jackson LA, Anderson EJ, Rouphael NG, Roberts PC, Makhene M, Coler RN, McCullough MP, Chappell JD, Denison MR, Stevens LJ, Pruijssers AJ. (2020) An mRNA vaccine against SARS-CoV-2 - preliminary report. The New England Journal of Medicine NEJMoa2022483.
Karthik K, Aravindh Babu RP, Dhama K, Chitra MA, Kalaiselvi G, Alagesan Senthilkumar TM, Raj GD (2020) Biosafety Concerns During the Collection, Transportation, and Processing of COVID19 Samples for Diagnosis. Archives of Medical Research S01884409(20)30889-4. doi: 10.1016/j.arcmed.2020.08.007.

Khandola A (2020) Coronavirus (COVID-19) origin: Cause and how it spreads. Available at

https://www.medicalnewstoday.com/articles/coronavirus-causes, accessed on 16 October 2020.

Kim JH, Kang M, Park E, Chung DR, Kim J, Hwang ES (2019) A Simple and Multiplex Loop-Mediated Isothermal Amplification (LAMP) Assay for Rapid Detection of SARS-CoV. Biochip Journal 13(4):341-351. doi: 10.1007/s13206-019-3404-3.

Klempner MS, Shapiro DS (2004) Crossing the species barrierone small step to man, one giant leap to mankind. New England Journal of Medicine 350: 1171-1172.

Ksiazek TG, Erdman D, Goldsmith CS, Zaki SR, Peret T, Emery S, Tong S, Urbani C, Comer JA, Lim W, Rollin PE (2003) A novel coronavirus associated with severe acute respiratory syndrome. New England journal of medicine 348: 1953-1966.

Lai T, Xiang F, Zeng J, Huang Y, Jia L, Chen H, Wu J, Xie J, Liu S, Deng W, Zheng W, Huang Y, Zhang Q, Luo Q, Mo F, Long L, Zhang W, Chen W, Han H (2020) Reliability of induced sputum test is greater than that of throat swab test for detecting SARSCoV-2 in patients with COVID-19: A multi-center cross-sectional study. Virulence 11(1):1394-1401. doi: $10.1080 / 21505594.2020 .1831342$.

Lei H, Li Y, Xiao S, Lin CH, Norris SL, Wei D, Hu Z, Ji S. (2018) Routes of transmission of influenza A H1N1, SARS CoV, and norovirus in air cabin: Comparative analyses. Indoor Air 28(3):394-403. doi: 10.1111/ina.12445.

Leung WK, To KF, Chan PK, Chan HL, Wu AK, Lee N, Yuen KY, Sung JJ (2003) Enteric involvement of severe acute respiratory syndrome-associated coronavirus infection. Gastroenterology 125: 1011-1017.

Liu DX, Fung TS, Chong KK, Shukla A, Hilgenfeld R (2014) Accessory proteins of SARS-CoV and other coronaviruses. Antiviral Research 109: 97-109.

Luo F, Liao FL, Wang H, Tang HB, Yang ZQ, Hou W (2018) Evaluation of Antibody-Dependent Enhancement of SARS-CoV Infection in Rhesus Macaques Immunized with an Inactivated SARS-CoV Vaccine. Virologica Sinica 33(2):201-204. doi: 10.1007/s12250-018-0009-2. 
Mackay IM, Arden KE (2015) MERS coronavirus: diagnostics, epidemiology and transmission. Virology Journal 12: 1-21.

Malik YS, Kumar N, Sircar S, Kaushik R, Bhat S, Dhama K, Gupta P, Goyal K, Singh MP, Ghoshal U, El Zowalaty ME, O R V, Yatoo MI, Tiwari R, Pathak M, Patel SK, Sah R, RodriguezMorales AJ, Ganesh B, Kumar P, Singh RK (2020) Coronavirus Disease Pandemic (COVID-19): Challenges and a Global Perspective. Pathogens 9(7):E519.

Menachery VD, Gralinski LE, Mitchell HD, Dinnon KH, Leist SR, Yount BL, Graham RL, McAnarney ET, Stratton KG, Cockrell AS, Debbink K (2017) Middle East respiratory syndrome coronavirus nonstructural protein 16 is necessary for interferon resistance and viral pathogenesis. MSphere 2: 1-12.

Mo HY, Xu J, Ren XL, Zeng GQ, Tan YX, Chen RC, Chan-Yeung M, Zhong NS (2005) Evaluation by indirect immunofluorescent assay and enzyme linked immunosorbent assay of the dynamic changes of serum antibody responses against severe acute respiratory syndrome coronavirus. Chinese Medical Journal (English) 118: 446-450.

Morawska L, Cao J (2020) Airborne transmission of SARS-CoV2: The world should face the reality. Environment International 139:105730.

Mullard A (2020) COVID-19 vaccine development pipeline gears up. Lancet. 395(10239):1751-1752. doi: 10.1016/S0140-6736(20)31252-6.

Nassar MS, Bakhrebah MA, MeoSA, Alsuabeyl MS, Zaher WA (2018) Middle East Respiratory Syndrome Coronavirus (MERS$\mathrm{CoV}$ ) infection: epidemiology, pathogenesis and clinical characteristics. European Review for Medical and Pharmacological Sciences 22: 4956-4961.

Papadakis MA, McPhee SJ, Rabow MW (2016) Medical Diagnosis \& Treatment. New York: McGraw-Hill Education. McGraw-Hill, New York.

Peiris JS, Lai ST, Poon LL, Guan Y, Yam LY, Lim W, Nicholls J, Yee WK, Yan WW, Cheung MT, Cheng VC (2003) Coronavirus as a possible cause of severe acute respiratory syndrome. The Lancet 361: 1319-1325.

Philips CA, Mohan N, Ahamed R, Kumbar S, Rajesh S, George T, Mohanan M, Augustine P (2020) One disease, many faces-typical and atypical presentations of SARS-CoV-2 infection-related COVID-19 disease. World journal of clinical cases 8(18):39563970. doi: 10.12998/wjcc.v8.i18.3956.

Rabaan AA, Al-Ahmed SH, Haque S, Sah R, Tiwari R, Malik YS, Dhama K, Yatoo MI, Bonilla-Aldana DK, Rodriguez-Morales AJ
(2020) SARS-CoV-2, SARS-CoV, and MERS-COV: A comparative overview. Infez Med 28(2):174-184. PMID: 32275259 .

Rabi FA, Al Zoubi MS, Kasasbeh GA, Salameh DM, Al-Nasser AD (2020) SARS-CoV-2 and Coronavirus Disease 2019: What We Know So Far. Pathogens 9: 231.

Rodriguez-Morales AJ, Bonilla-Aldana DK, Tiwari R, Sah R, Rabaan AA, Dhama K (2020) COVID-19, an emerging coronavirus infection: current scenario and recent developments an overview. Journal of Pure and Applied Microbiology 14(1): 0512. https://doi.org/10.22207/JPAM.14.1.02

Setti L, Passarini F, De Gennaro G, Barbieri P, Perrone MG, Borelli M, Palmisani J, Di Gilio A, Piscitelli P, Miani A (2020) Airborne Transmission Route of COVID-19: Why 2 Meters/6 Feet of Inter-Personal Distance Could Not Be Enough. International Journal of Environmental Research and Public Health 17(8):E2932.

Sharma R, Akhoury G (2020) 2019-nCoV: a worldwide concern and facts. Virus disease 16:1-8. doi: 10.1007/s13337-020-00633-8.

Sharun K, Tiwari R, Dhama J, Dhama K (2020) Dexamethasone to combat cytokine storm in COVID-19: Clinical trials and preliminary evidence. International Journal of Surgery 82:179-181. doi: $10.1016 /$ j.ijsu.2020.08.038.

Shim BS, Stadler K, Nguyen HH, Yun CH, Kim DW, Chang J, Czerkinsky C, Song MK (2012) Sublingual immunization with recombinant adenovirus encoding SARS-CoV spike protein induces systemic and mucosal immunity without redirection of the virus to the brain. Virology journal 21;9:215. doi: 10.1186/1743422X-9-215.

Sputnik V (2020) The first registered vaccine against COVID-19. https://sputnikvaccine.com/. 2020. Accessed 30 ${ }^{\text {th }}$ September 2020.

Tiwari R, Dhama K, Sharun K, Iqbal Yatoo M, Malik YS, Singh R, Michalak I, Sah R, Bonilla-Aldana DK, Rodriguez-Morales AJ (2020) COVID-19: animals, veterinary and zoonotic links. Veterinary Quarterly 40(1):169-182. doi: 10.1080/01652176.2020.1766725.

TOI Coronavirus vaccine (2020) From Covaxin to Russian vaccine roll out, here are all the updates regarding COVID-19 vaccine development. 2020. https://timesofindia.indiatimes.com/lifestyle/health-fitness/health-news/coronavirus-vaccine-fromcovaxin-to-russian-vaccine-roll-out-here-are-all-the-updatesregarding-covid-19-vaccine-

development $/$ photostory $/ 78362614 . \mathrm{cms}$ ?picid $=78362622$.

Accessed $30^{\text {th }}$ September 2020. 
Udugama B, Kadhiresan P, Kozlowski HN, Malekjahani A, Osborne M, Li VYC, Chen H, Mubareka S, Gubbay JB, Chan WCW (2020) Diagnosing COVID-19: The Disease and Tools for Detection. ACS Nano 14(4):3822-3835.

Wang MD, Jolly AM (2004) Changing virulence of the SARS virus: the epidemiological evidence. Bulletin of the World Health Organization 82: 547-548.

Weingartl H, Czub M, Czub S, Neufeld J, Marszal P, Gren J, Smith G, Jones S, Proulx R, Deschambault Y, Grudeski E (2004) Immunization with modified vaccinia virus Ankara-based recombinant vaccine against severe acute respiratory syndrome is associated with enhanced hepatitis in ferrets. Journal of virology 78: $12672-12676$.

Wernery U, Lau SK, Woo PC (2017) Middle East respiratory syndrome (MERS) coronavirus and dromedaries. The Veterinary Journal 220: 75-79.

World Health Organization (2020a) Coronavirus. https://www.who.int/health-topics/coronavirus\#tab=tab_3, accessed on 13 July 2020.

World Health Organization (2020b). DRAFT landscape of COVID-19 candidate vaccines - 28 September 2020. https://www.who.int/publications/m/item/draft-landscape-of-covid19-candidate-vaccines. 2020; Accessed 30 ${ }^{\text {th }}$ September 2020.

World Health Organisation (2020c) Middle East respiratory syndrome coronavirus (MERS-CoV). https://www.who.int/newsroom/fact-sheets/detail/middle-east-respiratory-syndromecoronavirus-(mers-cov), accessed on 16 October 2020.

Xu X, Gao X (2004) Immunological responses against SARScoronavirus infection in humans. Cellular \& Molecular Immunology 1: 119-122.

Xu RH, He JF, Evans MR, Peng GW, Field HE, Yu DW, Lee CK, Luo HM, Lin WS, Lin P, Li LH (2004) Epidemiologic clues to SARS origin in China. Emerging Infectious Diseases 10: 1030-1037.
Zhang CY, Wei JF, He SH (2006) Adaptive evolution of the spike gene of SARS coronavirus: changes in positively selected sites in different epidemic groups. BMC Microbiology 6: 88.

Zhang R, Li Y, Zhang AL, Wang Y, Molina MJ (2020) Identifying airborne transmission as the dominant route for the spread of COVID-19. Procedings of the National Academy of Sciences USA 117(26):14857-14863.

Zhong NS, Zeng GQ (2003) Our strategies for fighting severe acute respiratory syndrome (SARS). American Journal of Respiratory and Critical Care Medicine 168: 7-9.

Zhong NS, Zheng BJ, Li YM, Poon LL, Xie ZH, Chan KH, Li PH, Tan SY, Chang Q, Xie JP, Liu XQ (2003) Epidemiology and cause of severe acute respiratory syndrome (SARS) in Guangdong, People's Republic of China, in February. The Lancet 362: 1353-1358.

Zhong X, Yang H, Guo ZF, Sin WY, Chen W, Xu J, Fu L, Wu J, Mak CK, Cheng CS, Yang Y (2005) B-cell responses in patients who have recovered from severe acute respiratory syndrome target a dominant site in the $\mathrm{S} 2$ domain of the surface spike glycoprotein. Journal of Virology 79: 3401-3408.

Zhou F, Yu T, Du R, Fan G, Liu Y, Liu Z, Xiang J, Wang Y, Song B, Gu X, Guan L (2020) Clinical course and risk factors for mortality of adult inpatients with COVID-19 in Wuhan, China: a retrospective cohort study. The Lancet 395: 1054-1062.

Zhou T, Wang H, Luo D, Rowe T, Wang Z, Hogan RJ, Qiu S, Bunzel RJ, Huang G, Mishra V, Voss TG (2004) An exposed domain in the severe acute respiratory syndrome coronavirus spike protein induces neutralizing antibodies. Journal of Virology 78: 7217-7226.

Yatoo MI, Hamid Z, Parray OR, Wani AH, Ul Haq A, Saxena A, Patel SK, Pathak M, Tiwari R, Malik YS, Sah R, Rabaan AA, Rodriguez Morales AJ, Dhama K (2020) COVID-19 - Recent advancements in identifying novel vaccine candidates and current status of upcoming SARS-CoV-2 vaccines. Human Vaccines and Immunotherapeutics 1-14. doi: 10.1080/21645515.2020.1788310. 